\section{CIUDADES SATÉLITES PERIURBANAS EN SANTIAGO DE CHILE: PARADOJAS ENTRE LA SATISFACCIÓN RESIDENCIAL Y PRECARIEDAD ECONÓMICA DEL PERIURBANITA DE CLASE MEDIA ${ }^{1}$}

César Cáceres Seguel ${ }^{2}$

\section{Resumen}

La expansión periurbana de Santiago de Chile se relaciona al desarrollo de ciudades satélites privadas. Los proyectos construidos en la comuna de Lampa resultan interesantes de analizar dado que dan cuenta de la periurbanización de grupos socioeconómicos medios. Aunque la periurbanizacion de Santiago resulta ampliamente investigada, se observa un déficit de comprensión acerca del impacto que proyectos residenciales privados tienen en la calidad de vida del habitante. Mediante sesenta entrevistas con habitantes de las urbanizaciones Larapinta y Valle Grande, se constata una experiencia residencial definible como la felicidad

\section{PERI-URBAN SATELLITE TOWNS IN SANTIAGO, CHILE: CONTRADICTIONS BETWEEN RESIDENTIAL SATISFACTION AND THE FINANCIAL VULNERABILITY OF MIDDLE-CLASS PERI- URBAN DWELLERS ${ }^{1}$}

Cesar Cáceres Seguel ${ }^{2}$

\section{Abstract}

The peri-urban expansion in Santiago, Chile, is related to the development of private satellite towns. The projects developed in the municipality of Lampa deserve some analysis since they shed light on the establishment of emerging middleincome groups in peri-urban areas. Though the process of peri-urbanization of Santiago has been widely studied, the impact of private housing projects on the quality of life of inhabitants remains unclear. Through sixty interviews with inhabitants of Larapinta and Valle Grande, this paper confirms the paradoxical happiness of middle-class peri-urbanites. Such a contradiction 
paradójica del periurbanita de clase media. Esta surge de la satisfacción ante la conquista de estándares residenciales superiores, asociado a una precariedad económica surgida de una vida basada en la movilidad y exclusiva disponibilidad de equipamiento privado. Estos proyectos lejos de constituir oasis de calidad de vida, exhiben la vulnerabilidad de grupos medios con precarias herramientas para habitar la peri-urbia privada.

PALABRAS CLAVE: PERIURBANIZACION; CLASE MEDIA; SANTIAGO DE CHILE; CALIDAD DE VIDA; CIUDAD SATÉLITE

Recibido: 09-10-2014

Aceptado: 09-09-2015 emerges from the satisfaction related to the achievement of higher residential standards and the financial vulnerability derived from a lifestyle based on mobility and the availability of private facilities. Far from being a haven of livability, these projects show the vulnerability of middle-income groups with precarious tools to inhabit the private peri-urban sphere.

KEYWORDS: PERI-URBANIZATION; MIDDLE-CLASS; SANTIAGO, CHILE; QUALITY OF LIFE; SATELLITE TOWN.

Received: 09-10-2014

Accepted: 09-09-2015
1 El texto da a conocer parte de la tesis doctoral "Exploring the periurban residential areas in Santiago de Chile: The asymmetric residential model between Corporate and State residential areas in Lampa 2000-2010" desarrollada entre el 2009 y 2013 en el Departamento de Planificación Urbana de la Hafen City Universitat Hamburg. Investigación financiada por el programa de doctorado CONICYT-DAAD.

2 Alemania. Doctor en ciencias económicas y sociales, mención planificación urbana Hafen City Universität Hamburg. Correo electrónico: cesar.caceres@gmx.com.
1 This paper is based on the dissertation "Exploring the PeriUrban Residential Areas in Santiago, Chile: The Asymmetric Residential Model between Corporate and State Residential Areas in Lampa 2000-2010" conducted from 2009 to 2013 at the Department of Urban Planning, HafenCity University Hamburg. This research was funded by the CONICYT-DAAD doctoral program.

2 Germany. PhD in Economic and Social Sciences, with specialization in Urban Planning, HafenCity University Hamburg. Email: cesar.caceres@gmx.com. 


\section{Introducción}

La ciudad contemporánea se distingue por el auge de proyectos residenciales privados que han transformando el paisaje y los modos de vida urbana $^{3}$. Estos se representan como productos de una nueva fase de capitalismo donde las estrategias de acumulación surgen asociadas a la expansión de la propiedad privada y desposesión progresiva del derecho a bienes comunes en la ciudad $^{4}$. En el caso Latinoamérica se constata la multiplicación de proyectos como condominios cerrados o ciudades satélites que irrumpen como arquetipos de un modo de urbanización basada en la seguridad y exclusividad ${ }^{5}$. El caso de Santiago de Chile resulta interesante dado que muestra un proceso de expansión asociado en parte a la construcción de proyectos inmobiliarios en los bordes periurbanos ${ }^{6}$. Si bien se trata de un proceso ampliamente estudiado desde sus aristas políticas y ambientales, sabemos poco sobre el impacto que urbanizaciones privadas tienen en la calidad de vida de grupos socioeconómicos medios. Uno de los procesos sociales más relevantes de los últimos veinte años en Chile ha sido la expansión

3 Fischman, 1987; Dematteis, 1998; Mattos, 1999; Glasze, 2003; Janoschka, 2002; Paddison, 2001.

4 Harvey, 2005.

5 Caldeira, 2000; Roitman, 2003, 2004; Uribe, 2002; Cabrales y Canosa, 2002; Tella, 2003; Meyer y Bahr, 2004.

6 Salcedo y Torres, 2004; Hidalgo y Borsdorf, 2005; Ducci y Gonzalez, 2006; Lizama, 2007. del segmento socioeconómico medio. El sostenido crecimiento económico $(5,5 \%$ anual en los noventa), políticas públicas efectivas, aumento de capital educacional ${ }^{7}$, así como el incremento de la participación femenina en el mercado del trabajo $^{8}$, han permitido la disminución de la pobreza desde 38,6\% en 1990 a 14,4\% el 2011. Entre 1990 y 2007 los hogares considerados de estrato medio aumentaron cerca de 1,1 millones, sumándose a los 1.2 millones estimados a inicios de los noventa9 ${ }^{9}$. Atendiendo a datos de la encuesta Casen 2006, el segmento medio-bajo concentra el $24,4 \%$ de la población total del país, mientras que el 20,1\% se ubica en el estrato medio-alto ${ }^{10}$. Ahora, utilizando la capacidad de consumo como variable de clasificación, el año 2007 el segmento mediobajo (C3) concentraba el 25\% de la población del país, mientras que el segmento medio alto (C2) el 20\% ${ }^{11}$. Más allá de las diferencias de medida, existe consenso en reconocer este segmento como un cuerpo heterogéneo. De acuerdo a Contreras, Cooper y Herman ${ }^{12}$ se trata de un grupo heterogéneo, definido por una alta vulnerabilidad social. Lo precario de su ascenso social queda retratado en que el $48 \%$ de los definidos como

\footnotetext{
Torche y Wormald, 2004.

Arriagada y Sojo, 2012.

Franco et al, 2011, p. 18.

10 Espinoza y Barozet, 2009, p. 113.

11 Asociación Chilena de Empresas de Investigación de Mercado, 2008, p. 14.

12 Contreras, Cooper y Herman, 2005, p. 5-6.
} 
población pobre el 2001 fueron no pobres en $1996^{13}$. Esta precariedad es compartida por la OECD, quienes plantean que el segmento medio chileno es uno de los menos tolerantes de la región ${ }^{14}$. Esta alta fragilidad se explicaría tanto por su dependencia por el crédito de consumo como por limitaciones del sistema de protección social chileno, que ante episodios de cesantía, enfermedad, o jubilación, pueden arrastrar a las personas a episodios de movilidad descendente ${ }^{15}$. Si hasta los setenta esta precariedad se enfrentaba mediante el acceso a beneficios del Estado ${ }^{16}$, hoy el sujeto de clase media gestiona escenarios de incertidumbre vía el acceso a créditos de consumo ${ }^{17}$. El fuerte estímulo y presión social hacia el consumo, genera que las aspiraciones de estos grupos se distancien fuertemente de su nivel real de ingresos ${ }^{18}$. En grupos medios surge lo que Lipovetzky ${ }^{19}$ denomina como una felicidad paradójica, grupos disfrutando de una alta capacidad de consumo pero en contexto de alta precarización de sus condiciones laborales y económicas.

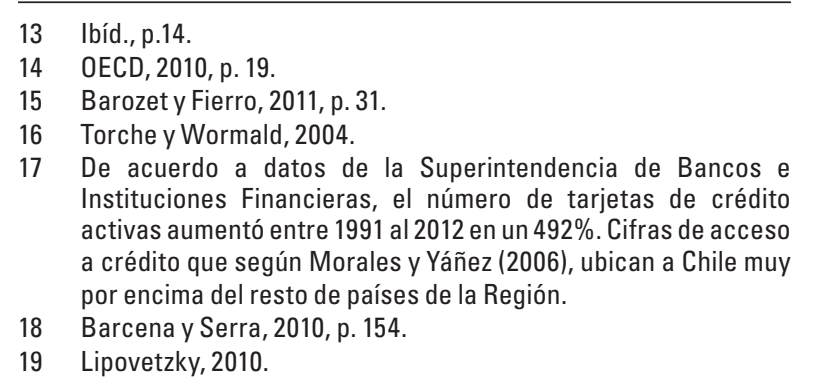

86 revista invi № 85 / Noviembre 2015 / Volumen N ${ }^{0}$ 30: 83-110
El sujeto de clase media chileno/a ha sido estudiado desde la perspectiva de su definición ${ }^{20}$, estructura ocupacional ${ }^{21}$, patrones de localización residencial ${ }^{22}$, hábitos de consumo ${ }^{23}$, sin embargo, no abundan estudios empíricos que exploren en la calidad de vida que estos grupos encuentran en proyectos residenciales privados. Parte relevante del análisis sobre el bienestar de grupos medios en Chile pasa por poner a prueba la noción de suburbia privada como espacio socialmente homogéneo y oasis de calidad de vida. Como destacan Cabrales y Canosa ${ }^{24}$ "detrás de esa unidad que reflejan los muros neo-medievales se esconde una amplia gama de diversidades, de matices que obligan a hacer exploraciones detalladas como prerrequisito para construir generalizaciones y modelizar el fenómeno". La comuna periurbana de Lampa resulta un caso de estudio interesante de analizar dado que su expansión reciente está asociada al desarrollo de ciudades satélites privadas enfocadas en segmentos medios. Mediante entrevistas con habitantes de los proyectos de Larapinta y Valle

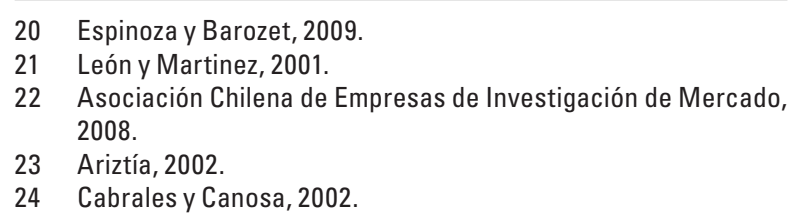

ARTÍCULO: Ciudades satélites periurbanas en Santiago de Chile: paradojas entre la satisfacción residencial y precariedad económica del periurbanita de clase media/ 
Grande, se indaga en las prácticas urbanas cotidianas y representación de calidad de vida de estos grupos. Dado el enfoque cualitativo del estudio no se pretende elaborar interpretaciones globales del fenómeno estudiado, sino entregar elementos empíricos y evidencias iniciales sobre el bienestar de grupos medios en la periurbia privada de Santiago. Se sostiene en este artículo que el éxodo hacia proyectos periurbanos privados abre interrogantes sobre el grado de satisfacción residencial y capacidad de estos grupos para sostener dicho estilo de vida. Son grupos que gozan de mayor nivel adquisitivo, se muestran capaces de decidir con mayor libertad donde vivir, sin embargo iconstituyen estos proyectos una conquista indiscutida de calidad de vida para estos grupos?

Este estudio se construye desde una noción de satisfacción residencial como un proceso evaluativo de las características sociales y materiales de la comunidad $^{25}$. Ahora bien, considerando que se trata de comunidades periurbanas se define un modelo de análisis que reconoce el carácter multi-escalar de la vida cotidiana de estos grupos. Dado lo anterior, el enfoque de análisis de comunidades propuesto por Liepins ${ }^{26}$ resulta pertinente. Esta autora reconoce una comunidad como un constructo dinámico compuesto por elementos materiales, simbólicos y políticos, que requiere de un análisis

25 Mulligan et al, 2004; Vidal y Pol, 2005. 283.

26 Liepins, 2000.

ARTíCULO: Ciudades satélites periurbanas en Santiago de Chile: paradojas entre la satisfacción residencial y precariedad económica del periurbanita de clase media/

César Cáceres Seguel integral. Se llevaron a cabo 60 entrevistas con habitantes de los proyectos Larapinta y Valle Grande (30 habitantes por cada proyecto). El cuestionario de preguntas abordó los siguientes temas. (1) El análisis de prácticas cotidianas de acceso a recreación, salud, educación y consumo, a escala local y metropolitana. Una segunda parte indagó en (2) aspectos subjetivos como percepción de seguridad, apego al barrio, y relación con vecinos. Para abordar estos asuntos se usaron dos tipos de preguntas. (1) Preguntas abiertas donde el entrevistado evaluó asuntos subjetivos asociados a seguridad, satisfacción con el entorno residencial y calidad de vida. Así como (2) preguntas que incorporaron una escala de valoración que permitió tener una noción sobre la frecuencia de uso de espacios públicos, evaluación del equipamiento barrial, y rutinas de acceso a atención de salud o centros de consumo. El rango etario de los participantes se ubicó entre los 25 a 60 años aproximadamente. Las entrevistas se realizaron durante septiembre del 2010 y una segunda fase en marzo del 2011. En la sección siguiente se describe brevemente el caso de estudio así como se analiza el concepto urbano asociado a las ciudades satélites desarrolladas en Lampa. La tercera parte presenta los principales resultados del proceso de entrevista. Finalmente, se discuten los principales hallazgos y conclusiones del estudio.

revista invi № 85 / Noviembre 2015 / Volumen № 30: 83-110 


\section{Casos de estudio: Lampa, un polo residencial periurbano para grupos medios}

Lampa es una comuna periurbana ubicada a 37 kilómetros al norte de la comuna de Santiago. Muestra un patrón de urbanización disperso en cuatro asentamientos: Sol de Septiembre, Batuco, Estación Colina y Lampa. De acuerdo a datos sobre evolución histórica de predios residenciales ${ }^{27}$, el 68\% del desarrollo urbano de esta comuna se concentra en la última década. Durante el período 2002-2010 se observa un intenso desarrollo residencial (13.023 nuevas unidades) que la ubica como la segunda comuna con mayor crecimiento porcentual de viviendas a nivel nacional. Cifras preliminares señalan que la comuna recibió entre en el 2002-2012 cerca de 39.323 nuevos residentes (79.421 el 2012 en comparación a 25.033 el año 2002), lo que implica una variación de población

27 Dato disponible en Servicio de Impuestos Internos.
2002-2012 del 98\% (tercera mayor variación porcentual a nivel país). Esta fuerte expansión residencial está directamente ligada a la reforma al Plan Regulador Metropolitano de Santiago en 1997. Esta reforma incorporó la provincia de Chacabuco (comunas de Til Til, Colina y Lampa) como parte del área de expansión urbana de Santiago ${ }^{28}$. En 1996 el Ministerio de Vivienda y Urbanismo modificó el Plan metropolitano de Santiago, incluyendo al área urbanizable la provincia de Chacabuco y sus 15.242 hectáreas de suelo disponible. Si el Plan Metropolitano de 1994 fijaba una imagen objetivo basada en una metrópolis densa y contención de la expansión urbana, dos años más tarde la institucionalidad crea una normativa que permite la generación de proyectos periurbanos asociado al cumplimiento de una serie de estándares de equipamiento, mixtura social y tamaño mínimo. Esta normativa se definió bajo el nombre de "urbanización por condiciones"29 y fue impulsada por el Ministerio

28 La oportunidad de negocio que representaban comunas periurbanas próximas al Gran Santiago promovieron operaciones de lobby que buscaron reformular restricciones impuestas a la urbanización de suelo agrícola definidas por el plan regulador metropolitano de 1994 (Poduje, 2006, p. 261).

29 De acuerdo a esta normativa un nuevo proyecto residencial debe cumplir con los siguientes requisitos: (1) una densidad mínima de 85 habitantes por hectárea, (2) una urbanización de al menos 300 hectáreas, (3) de las viviendas construidas $30 \%$ debe ser vivienda subsidiada entre 300 y 1500 UF. De estos $30 \%$ debe albergar vivienda con densidades entre 401 a 500 habitantes (vivienda social). (4) el proyecto debe incluir equipamiento como centro salud, colegio, jardín infantil, bomberos, policía, infraestructura deportiva y parques.

ARTÍCULO: Ciudades satélites periurbanas en Santiago de Chile: paradojas entre la satisfacción residencial y precariedad económica del periurbanita de clase media/ 
de Vivienda y Urbanismo de la siguiente manera: "permitir la creación de ciudades nuevas en áreas con aptitudes para el establecimiento de nuevos componentes del sistema urbano regional, diferenciados y separados de las actuales ciudades y de la metrópoli, evitando la conurbación y el crecimiento en extensión" ${ }^{\prime 30}$.

\section{FIGURA 1. LOCALIZACIÓN DE LAS CIUDADES SATÉLITES ESTUDIADAS}

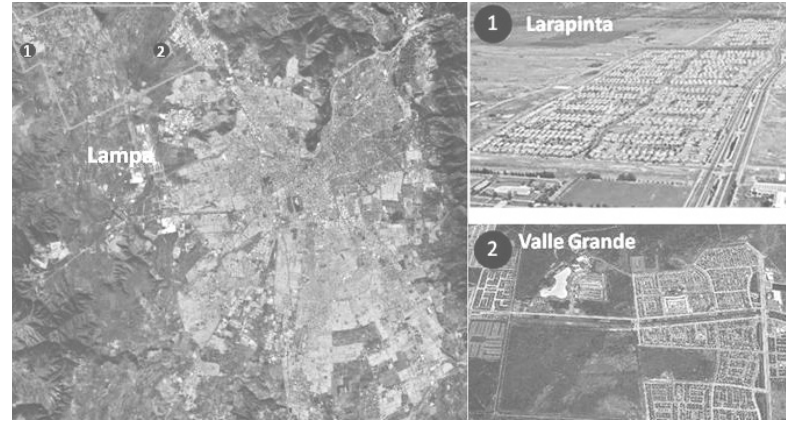

Fuente: Google Earth

En el caso de la comuna de Lampa esta reforma determinó la creación de un área de desarrollo condicionado (ADUP) de 350 hectáreas para crecimiento en extensión a la ciudad de Lampa (alberga actualmente la ciudad satélite Larapinta). Asimismo, estableció 310 hectáreas para el desarrollo de proyectos de desarrollo condicionado en el asentamiento de Batuco, 205 hectáreas en el asentamiento de

30 Ministerio de Vivienda y Urbanismo, 1996, p. 30.
Estación Colina, y 54 hectáreas en el asentamiento de Sol de Septiembre.Se crearon además zonas de desarrollo condicionado de 1.214 hectáreas en el sector El Alfalfal y 1.344 de superficie urbanizable en el sector de Lipangue.

¿Qué concepto urbano está detrás de estos proyectos? Las ciudades satélites periurbanas constituyen mega-proyectos residenciales de alrededor de trescientas hectáreas, proyectados para albergar hasta cien mil habitantes. Como se señaló, se rigen por una normativa definida como "urbanización por condiciones" que fija estándares de equipamiento urbano, así como el desarrollo de vivienda de tipo subsidiada y vivienda social. En la ciudad satélite las empresas revisitan propuestas urbanísticas clásicas como la "ciudad jardín" de Howard y "unidad de barrio" de Perry, proponiendo asentamientos basados en un concepto de vida barrio con stock de equipamiento urbano básico (colegios, supermercados, clínicas, comercio minorista, bomberos, clubes deportivos, entre otros). Estas características sugieren que el desarrollo de ciudades satélites no debe ser leído como una nueva fase de suburbanización monofuncional clásica, sino, muestra la sofisticación de la industria inmobiliaria hacia proyectos residenciales multifuncionales que exaltan un diseño y experiencias integrales de vida de barrio. Esta transición es destacada por la empresa inmobiliaria que ejecuta el proyecto Valle Grande: 
"La oportunidad de crear una nueva ciudad permite una planificación adecuada generar condiciones de vida del mejor nivel para cualquiera de los estratos socioeconómicos que se emplacen, con buenos estándares viales, adecuada provisión de áreas verdes y espacios abiertos, equilibrada oferta de servicios, equipamiento y recreación"131.

La fase empírica aborda el estudio de dos ciudades satélites en Lampa: el proyecto Larapinta y Valle Grande. (1) La ciudad satélite "Larapinta" fue construida, y administrada, por el Holding inmobiliario Socovesa. Socovesa es un grupo inmobiliario con concentra el 5\% del total del mercado inmobiliario chileno. En 389 hectáreas la empresa proyectó el desarrollo de 10.376 viviendas para aproximadamente 51.880 habitantes. Al año 2010 el proyecto mostraba un avance de alrededor de diez mil habitantes en 2.500 viviendas construidas. (2) El proyecto "Valle Grande" es propiedad del Consorcio Valle Grande perteneciente en un 67\% al grupo económico Angelini, así como compañías

31 Estudio descriptivo del proyecto encargado por el Ministerio de Vivienda y Urbanismo y Ministerio de Transporte (Sociedad Inmobiliaria Valle Grande, 2003). de seguros pertenecientes a BiceCorp, Holding FFV-Fernandez León, y Holding CorpGroup. Se proyecta la construcción de 25 mil viviendas para 100 mil habitantes. Al año 2010 el proyecto contaba con 2.800 viviendas albergando aproximadamente once mil habitantes. Como se mencionó, un rasgo propio de estos proyectos es la mezcla de usos residenciales y equipamiento urbano básico. Un rasgo común de ambos proyectos es que fijan como cliente objetivo familias pertenecientes a segmentos medios. En Larapinta el rango de precios de viviendas oscila entre 900 a 2.300 $\mathrm{UF}^{32}$ (US\$ 35.000 a US\$ 89.540), mientras que en el proyecto Valle Grande las viviendas muestran un rango de precios entre 1.150 a 3.043 UF (US\$ 44.770 a US\$ 118.470$)^{33-34}$. Al analizar los estudios de impacto urbano es explicita la focalización en grupos socioeconómicos medios. La empresa Socovesa define de la siguiente forma el proyecto de ciudad satélite Larapinta: "una morfología urbana conformada por viviendas aisladas y pareadas, de uno, dos y tres pisos, diseñados en base a

32 La Unidad de Fomento (UF) es una medida que se reajusta en forma diaria según la variación del Índice de Precios al Consumidor (IPC) del mes anterior.

33 Una revisión del precio de viviendas en el mercado inmobiliario privado de Santiago y sus comunas periurbanas muestra un rango entre 750 UF (Colina) hasta 18.000 UF. Es posible plantear a grosso modo que los segmentos medios emergentes acceden a viviendas entre 750 a 2000 UF, mientras que segmentos medios-alto se ubican entre 3.000 a 4.500 UF aproximadamente. Como dato, el subsidio estatal para grupos medios emergentes financia viviendas hasta 2.200 UF.

34 Año 2010. 
diferentes tipologías con diferentes materiales, de modo de fortalecer el concepto de diversidad de identidad, de particularidad en relación a la repetición monótona y uniforme de los barrios de viviendas económicas"135. En el caso del proyecto Valle Grande, el estudio de impacto urbano define de la siguiente manera su focalización en el segmento medio: "El proyecto Valle Grande de Santiago se orienta a satisfacer la demanda por viviendas proveniente de los estratos D, C3 y C2, es decir, viviendas con valores desde menos de UF 500 hasta viviendas de UF $2000^{1136}$.

\section{Resultados del proceso de entrevistas}

Se entrevistaron treinta habitantes de la ciudad satélite de Larapinta e igual número en el proyecto Valle Grande. La selección de entrevistados buscó (1) cubrir un rango etario amplio, (2) participación de hombres y mujeres, así como (3) abarcar viviendas de distinto precios (nivel socioeconómico del habitante). Para el proceso de entrevista se optó por una estrategia basada en el reclutamiento individual de participantes. En una primera conversación se explicaron los objetivos y alcances del estudio. Una vez que la persona aceptaba participar del estudio se procedió inmediatamente

35 Estudio descriptivo del proyecto encargado por el Ministerio de Vivienda y Urbanismo y Ministerio de Transporte (Socovesa, 2003, p. 12).

36 Sociedad Inmobiliaria Valle Grande, 2003. a realizar la entrevista. A continuación se presentan los principales resultados del proceso.

\section{DESCRIBIENDO EL ÉXODO HACIA LA CIUDAD DEL CATÁLOGO}

La primera parte de la entrevista indagó en antecedentes como año del éxodo hacia la ciudad satélite, comuna de origen, así como acerca de las razones que primaron al decidir migrar hacia la ciudad satélite. Las entrevistas retratan un grupo que desde el año 2005 migró desde comunas del Gran Santiago como Conchalí, Renca, Recoleta, Huechuraba, San Bernardo, San Miguel, Macul, La Cisterna. El perfil del habitante habla fundamentalmente de familias jóvenes con estudios superiores, así como un segundo grupo relacionado a jubilados que optaron por alejarse de Santiago (en algunos casos siguiendo a sus hijos). Consultados sobre los factores que pesaron en la decisión de localizarse en Lampa, se reconoce que estos proyectos fueron una opción económicamente "realista" de acceder a valores urbanos como: mayor tamaño de patio, más dormitorios, disponibilidad de áreas verdes y seguridad. Se hizo hincapié en el hecho que acceder a similares estándares residenciales dentro del Gran Santiago resultaba inaccesible de acuerdo a sus posibilidades de endeudamiento bancario. 


\section{FIGURA 2. VIVIENDAS UNIFAMILIARES EN LA CIUDAD SATÉLITE LARAPINTA, LAMPA}

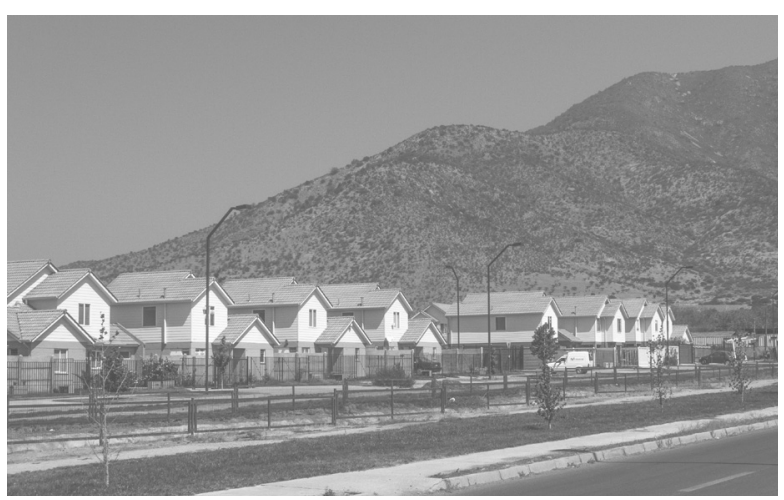

Fuente: Autor

Llegamos de Maipú hace cinco años, nosotros elegimos acá porque no queríamos vivir en Maipú o Puente Alto donde todas las casas están amontonadas. Acá hay más espacio, yo ahora tengo un patio que es el doble de lo que tendría en una casa en Santiago, mi casa no es pareada, en mi entrada de autos puedo tener dos autos cómodos. Una casa de estas mismas condiciones en Santiago nos saldría el doble. (Carolina, Larapinta)

Vivía en Macul y nos vinimos el 2008 (...)... sabes qué pasa, mi primera vivienda fue un departamento del gobierno, tú te levantabas con sound y te acostabas con corridos, además de las tomateras y los insultos. Tengo una hija que quiero darle mejor calidad de vida, cuando pensamos en meternos en esta deuda lo hicimos pensado en mi hija, en un mejor bienestar, mejor entorno, otra calidad de vida en cuanto a vecinos y amigos. (Elisa, Larapinta)
Se perfila un sujeto que no solo busca el sueño de la casa propia sino que significa el éxodo como la búsqueda de valores residenciales como seguridad, oferta de áreas verdes, más espacio. El salto periurbano no se representa desde el deseo de huida de la ciudad, por el contrario como búsqueda de atributos residenciales negados en sus barrios de origen. Si para algunas familias de estrato medio comprar un departamento en comunas centrales del Gran Santiago se explica por la revalorización de la proximidad como valor central de calidad de vida. Para estas familias el bienestar urbano radica en acceder a barrios habitables. Hay en esta representación del cambio al hogar periurbano un siguiente factor asociado con el acceso a "otro nivel de vecinos". En estos proyectos el/la periurbanita de grupo medio reivindica su derecho a redefinir su hábitat exaltando sus nuevas identidades y diferencias. La ciudad satélite es significada tanto como oportunidad de acceder a atributos residenciales superiores, como un capital físico-simbólico que permite expresar territorialmente su desplazamiento y diferenciación social.

ARTÍCULO: Ciudades satélites periurbanas en Santiago de Chile: paradojas entre la satisfacción residencial y precariedad económica del periurbanita de clase media/ 
FIGURA 3. PUBLICIDAD INVITANDO A FAMILIAS OUE ACCEDIERON A SUBSIDIO PARA LA CLASE MEDIA A MIGRAR HACIA LA CIUDAD SATÉLITE DE VALLE GRANDE

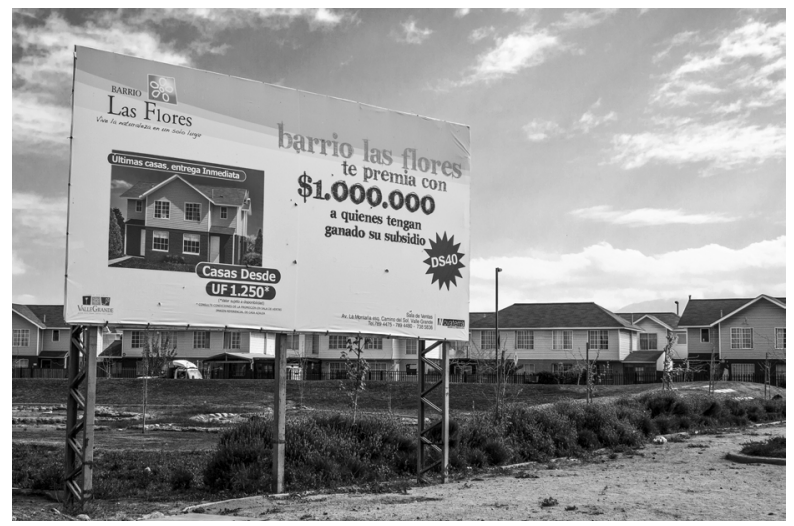

Fuente: Autor

\section{PRÁCTICAS RECREATIVAS Y VIDA COMUNITARIA, UNA NUEVA RELACIÓN CON EL ENTORNO}

El agente inmobiliario es hábil en transformar en oportunidad de mercado la percepción de déficit por áreas verdes y equipamiento barrial identificada por el habitante de ciudad chilena. La ciudad satélite se propone como un espacio residencial multifuncional, se establece un sistema de áreas verdes y espacios recreativos que sirven de eje articulador de zonas residenciales. Este énfasis en el espacio público encuentra una positiva evaluación de parte del habitante, hecho visible en que el 67\% de los entrevistados considera los espacios públicos y recreativos como de buena calidad. Consultados sobre la frecuencia de uso de espacios públicos como parques, avenidas o ciclo vías, el $50 \%$ de los entrevistados señalan que generalmente una vez por semana realizan actividades recreativas como correr, salir a caminar, u ocupar plazas; mientras que el $23 \%$ señala realizarlo dos veces por semana.

Con las niñas salimos a las plazas dos o tres veces a la semana, eso no lo hacía en la comuna donde vivíamos porque no teníamos algo cerca, para ir a una plaza teníamos que tomar el auto e irnos al paradero 9 de la Gran Avenida donde había un parque. Ir caminando a una plaza es algo que me gusta, aqui puedes salir con los niños en los coches o bicicletas tranquilamente, uno se siente seguro, es una calidad de vida que no teníamos donde vivíamos. Acá tienes más espacio, no andamos tan encima, eso provoca menos roces menos caras tensas. (Daniela, Larapinta)

Las plazas son buenas porque hay hartos árboles. Por ejemplo yo vengo con mi bebé y me quedo toda la tarde, es agradable, mantienen limpio, el pasto corto. Ha llegado harta gente con niños chicos y los fines de semana se llenan las plazas. Aqui me siento segura, salgo a correr hasta en la noche, corro por el camino hacia el tren y me devuelvo... ningún problema. No me arrepiento de haberme venido porque es otra calidad de vida, acá hay parques, en otras comunas hay solo plazas chicas. (Alejandra, Valle Grande)

El acceso a áreas verdes y espacios públicos de calidad aparece como uno de las conquistas más importantes señaladas por el/la habitante. Para entender estos resultados es necesario situarlos en 
contexto. El 62,9\% de los encuestados en la "Encuesta de percepción de calidad de vida urbana"37 señala hacer nulo o casi nulo uso de espacios deportivos de su barrio, así como el 51, 3\% señala un nulo o casi nulo uso de parques y plazas. Esta alta valoración y uso de espacio públicos muestra empresas inmobiliarias que no solo se muestran capaces de instalar nuevos paisajes residenciales, sino también de actuar a nivel cognitivo, incentivando una nueva relación entre habitante y entorno residencial que supera los límites de la vivienda y se apropia del espacio público. Discrepando de la imagen del urbanita chileno poco interesado en utilizar espacios públicos, la evidencia aquí exhibida señala que el habitante utiliza intensivamente tales espacios apenas se ofrecen áreas recreativas accesibles y de calidad.

Explorando en esta nueva relación entre habitante y su entorno, surge el atributo de la tranquilidad como un valor que explica sustancialmente su evaluación del proyecto. La conquista de tranquilidad se asocia a tres ámbitos. (1) Asociada a una vida en entornos semi-rurales, (2) un diseño urbano que brinda mayor espacio entre viviendas, disminuyendo así episodios de contaminación acústica. Y (3) una tranquilidad asociada al escape de eventos violentos existentes (robos) en la ciudad. Consultado sobre su percepción de seguridad el 88\% de los entrevistados manifiesta sentirse seguro viviendo en estas urbanizaciones. Este dato es significativo al compararlo con la encuesta de seguridad

Ministerio de Vivienda y Urbanismo, 2011.

\section{FIGURA 4. EL ACCESO A ÁREAS VERDES, INACCESIBLE EN SUS BARRIOS DE ORIGEN,APARECE COMO ELEMENTO ALTAMENTE VALORADO POR LAS FAMILIAS}

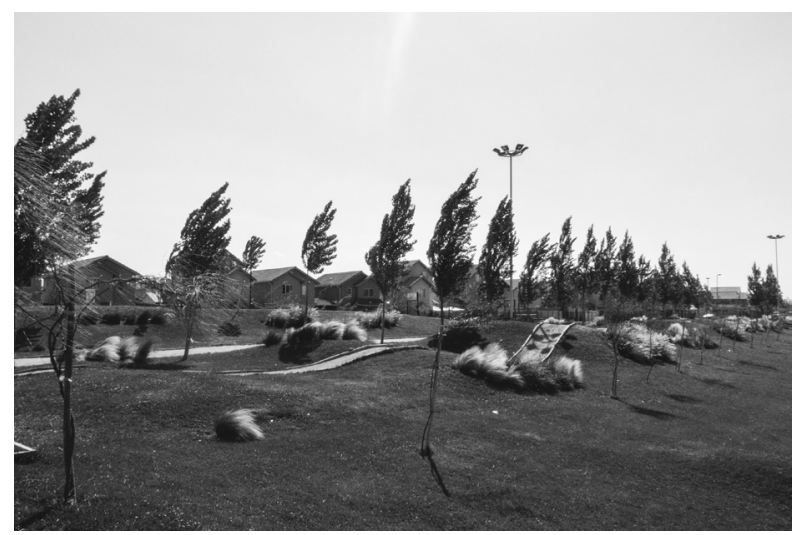

Fuente: Autor

ciudadana 2012, la que muestra que el 47,7\% de encuestados manifiesta sentirse, un poco, o muy inseguro de caminar solo en su barrio. Esta valoración de la ciudad satélite como lugar seguro contribuye necesariamente a esta nueva relación entre el habitante y el espacio público del barrio.

Uno gana en la calidad para los niños, en tranquilidad para ellos. No volvería a Santiago por la seguridad, acá la mayoría nos sentimos seguros. Me siento segura que mi hijo vaya al colegio en bicicleta (...) La seguridad prima por sobre que mi hijo se ha enfermado y hemos tenido que salir en taxi a Santiago, con el costo que significa... a pesar de eso. (Elizabeth, Larapinta) 
Ahora bien, un aspecto relevante de analizar en el estudio sobre calidad de vida en estos proyectos dice relación con la vida comunitaria. Se consideró relevante abordar este asunto desde dos ámbitos: (1) interacción entre vecinos y (2) organización comunitaria para instalar demandas a la empresa o municipio. En lo relativo a la relación entre vecinos los resultados muestran lo siguiente:

Lo mejor para mí es mi casa, el espacio, el patio. Tu vecino no te molesta, es gente decente; pero no ves a nadie! es muy solo. En mi [anterior] casa me sentaba afuera y veía a mis vecinos, aquí estaría muy mal visto si yo agarro mi tejido y me siento en la calle a tejer. Además mi familia viene poco porque es muy caro, y yo no puedo salir a cada rato. Mi hija tiene siete años, me dice "ya llegamos a la cárcel bonita"... ella se siente oprimida aquí, se siente encerrada, echa de menos a sus amigas del barrio. (Aida, Valle Grande)

Aquí cada cual hace su vida, hay muy poca comunicación entre los vecinos, uno se saluda y listo. (Johanna, Larapinta)

La ciudad satélite se representa como una conquista de valores paisajísticos, seguridad y espacios públicos, que conlleva costos expresados en el distanciamiento de redes afectivas y sociales construidas en sus barrios de origen. Las entrevistas describen una vida social regulada por un comportamiento tácito de vida familiar y diurna. Lo anterior perfila la ciudad satélite como una conquista de barrio disfrutable en familia más que asociado a una vida comunitaria compleja. Un aspecto interesante de mencionar es que aunque la vida social se representa reducida al saludo cotidiano, las redes comunitarias aparecen más densas cuando se activan desde la necesidad de solicitar alguna mejora o demanda específica a la empresa o municipio.

La mayoría de la gente contacta directamente a Socovesa y no a la municipalidad. El año pasado hicimos una protesta en la sala de venta por el tema de la seguridad porque ya no se podía dormir, así que pusieron guardias privados. (Elisa, Larapinta)

Nosotros reclamamos a la constructora y nos han solucionado las cosas, por ejemplo, la empresa cambió los árboles en mi avenida a plátano oriental, entonces, mi marido llamó para que las cambiaran porque producen alergia, así que rápidamente los cambiaron. (Olaya, Valle Grande)

La vida suburbana ha sido definida como una antítesis de comunidad y prevalencia de vida privada, sin embargo, la evidencia de este estudio sugiere que conviene mirar con detención este proceso. Estas entrevistas muestran un cambio en como el/la habitante percibe su posición en la gobernabilidad del espacio residencial, una transición desde un residente pasivo frente a los cambios y decisiones relativas a su entorno residencial, hacia una autodefinición de habitantecliente capaz de exigir la calidad urbana ofrecida en el catálogo del proyecto. Esta idea de habitantecliente fue confirmada por el municipio de Lampa 
donde se reconoce que asociado a la construcción de ciudades satélites emerge una comunidad que presiona por respuestas rápidas a sus demandas, así como por lógicas más horizontales de gobierno del espacio residencial:

La gestión local se hace más compleja por todo lo que significa manejar una Zoduc (...) la comunidad local está pendiente de si se cumple esto o lo otro, debes tener mayor cuidado en lo que el municipio hace porque estas en observación, (Funcionario de municipio de Lampa)

\section{ACCEDIENDO A SERVICIOS BÁSICOS: EL DÍA DESPUÉS DEL ÉXTASIS PERIURBANO}

Considerando el acceso a servicios y equipamiento urbano básico como una variable central en la evaluación de calidad de vida urbana, se consideró importante indagar en las rutinas cotidianas de acceso a salud, comercio y educación. Consultados sobre el lugar de estudio el 64\% de los entrevistados señalan que sus hijos (o nietos) asisten a jardines infantiles o colegios localizados en la ciudad satélite, $20 \%$ señala enviar a sus hijos a colegios dentro del Gran Santiago, mientras que el $16 \%$ asiste a colegios en el centro urbano de Lampa. Los datos muestran ciudades satélites con una alta capacidad de contener la demanda por educación pre-escolar, básica y media. En lo referido a atención médica el 70\% señala atenderse en centros médicos privados fuera de la ciudad satélite (30\% de este grupo señala ser usuario de un centro médico específico en el Mall Plaza Norte: Integramedica). El 30\% restante señala ser usuario de hospitales públicos en Santiago. El nivel de uso de centros médicos ubicados en la ciudad satélite es bajo, ya sea por el costo de la atención o por la falta de especialistas, el habitante resuelve la necesidad de atención médica fuera del proyecto. En el caso de prácticas de consumo, el 26\% de los entrevistados señala comprar productos básicos en el supermercado de la ciudad satélite, el 74\% restante asegura comprar regularmente en supermercados o ferias del comunas dentro del Gran Santiago (De estos: 24\% en supermercados de Mall Plaza Norte, 28\% en supermercado Lider Quilicura, y 22\% en la Feria la Vega y supermercados mayoristas, en comunas centrales como Santiago y Recoleta). 


\section{FIGURA 5. COLEGIO PROPIEDAD DE LA EMPRESA CONSTRUCTORA DEL PROYECTO CIUDAD SATÉLITE LARAPINTA.}

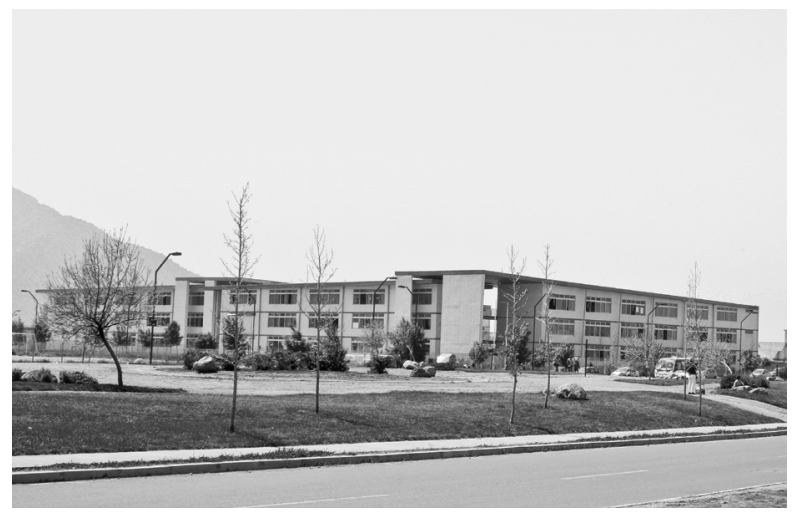

Fuente: Autor

A partir del análisis de rutinas de acceso a servicios y equipamiento básico, surgen cuatro observaciones relevantes. (1) Aunque las ciudades satélites se promocionan como asentamientos con altos grados autonomía funcional la evidencia muestra que con excepción de educación su impacto en rutinas de acceso a consumo y atención médica es baja. (2) Aunque la literatura urbana destaca el impacto positivo que barrios multifuncionales tienen sobre la calidad de vida del habitante ${ }^{38}$, la evidencia aquí exhibida muestra que si dichos servicios no muestran atributos de calidad o precio, el/la habitante simplemente no los utiliza. (3) Estos reportes resultan evidencia empírica

38 Knoxy Pinch, 2006; Frey, 1999.

\section{FIGURA 6. TRANSPORTE PÚBLICO EN EL PROYECTO LARAPINTA.}

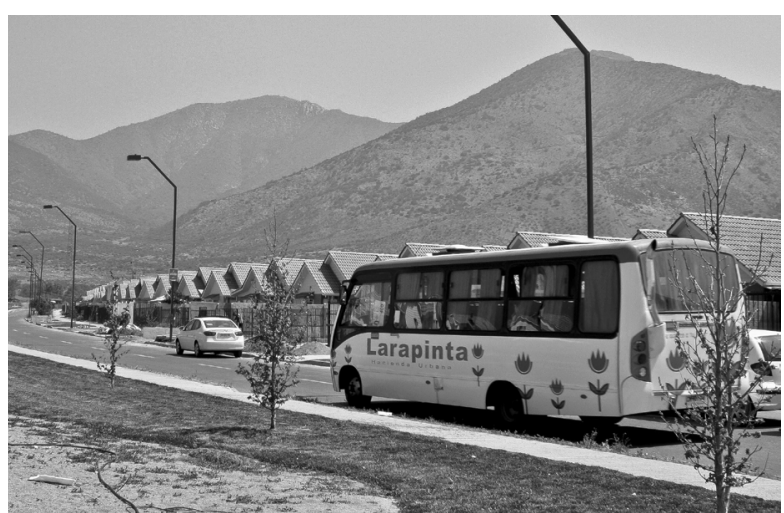

Fuente: Autor

que respalda la idea del mall (en este caso Mall Plaza Norte) como centros urbanos articuladores de macrozonas residenciales periféricas. (4) La movilidad a escala metropolitana se instala como condición básica para este habitante. Esto es relevante porque considerando la ausencia de Transantiago en estos proyectos. La disponibilidad de automóvil surge como factor básico de bienestar. Para familias con movilidad propia la ciudad satélite es la oportunidad de experimentar una vida SUVurbana, donde el automóvil permite ensamblajes poli-nodales y flexibles de vida cotidiana. Mientras que para usuarios de transporte público, la residencia periurbana implica frecuencias de buses limitadas a horarios 
diurnos, así como el pago doble por tramo (Bus ciudad satélite + Transantiago).

El pasaje es caro porque los buses no funcionan con tarjeta BIP porque son buses privados, son 2.700 diarios multiplicado por 20 días, casi sesenta mil pesos mensuales (...) aquí el costo de vida nos subió un 30\% por el costo de transporte. (Manuel, Larapinta)

La locomoción es mala en las mañanas y los fines de semana. Aquí hay personas que hacen turnos y para ellos la llegada en la mañana y la salida en la noche son complicadas. Los buses no funcionan con tarjeta BIP porque son buses privados (...) la gente pide el Transantiago porque también somos parte de la Región Metropolitana. (Regina, Larapinta)

Sumado a los problemas de transporte, un siguiente factor que impacta en la evaluación de calidad de vida dice relación con la localización exclusiva de equipamiento barrial de tipo privado e.g. colegios, centros médicos, clubes deportivos. La normativa que rige estos proyectos exige la localización de equipamiento urbano según módulos de población. Al momento de realizar este estudio los proyectos contaban con equipamiento tales como colegios, centros de salud, gimnasio, bomberos y supermercados. Lo interesante de destacar es que la normativa no especifica el carácter público o privada del equipamiento. Este detalle significa para la empresa una oportunidad de negocio no solo asociada a la venta de casas, sino también a la provisión de servicios y equipamiento de uso cotidiano. En el caso de Larapinta la empresa en propietaria de colegios y clubes deportivos. El consorcio Valle Grande es a su vez propietario de colegios y del transporte público que conecta con Santiago. Como se muestra en las entrevistas siguientes, la alta satisfacción con el diseño y seguridad del proyecto se matiza a partir del descontento que produce vivir en asentamientos donde el acceso a servicios urbanos básicos está absolutamente pre-formateado y dirigido por la empresa. Una disconformidad asociada a habitar bajo régimen de urbanidad-transbank, donde servicios públicos como salud, transporte, o colegios, son ofrecidos exclusivamente en régimen privado.

Aquí faltan multicanchas... hay un Club House pero hay que pagar. Acá el nivel socioeconómico es variable, hay gente que tiene más estudios, gente de clase media, pero también hay clase baja, entonces necesitamos multicanchas gratuitas para los niños. (Johanna, Larapinta)

No hay consultorio porque como lo quisieron hacer $A B C 1$, aunque no es la realidad de la gente aquí, aquí mucha gente tiene FONASA. Entonces hay que tener plata para llevarlo al Mall Plaza Norte, pero no tenemos como llegar. Si no tienes auto no te puedes mover a esas comunas que están cercanas. (Catalina, Valle Grande) 


\section{FIGURA 7. CLUB DEPORTIVO PRIVADO EN LA CIUDAD SATÉLITE VALLE GRANDE}

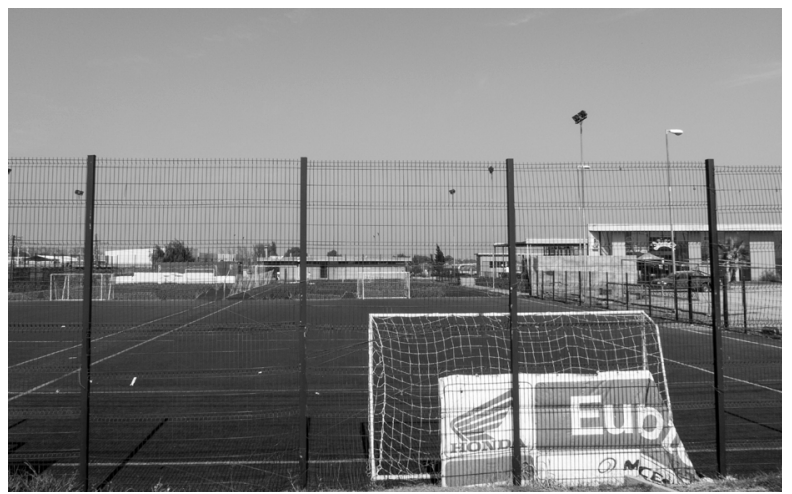

Fuente: Autor

Paradojalmente aunque optan por una vida en asentamientos privados, el/la habitante exige el desarrollo de una "mini ciudad" con servicios e infraestructura de carácter público. Esta aspiración muestra dos dificultades. Primero, el tamaño poblacional de estos proyectos no muestra la suficiente masa crítica capaz de viabilizar la localización de equipamiento de salud o comercio de mayor complejidad. Segundo, la generación de asentamientos privados aislados del centro urbano principal de Lampa, entra en conflicto con la planificación territorial que instituciones como Carabineros o Bomberos realizan. El desfase entre

\section{FIGURA 8. NIÑNOS JUGANDO EN LA CALLE EN LARAPINTA. ENTREVISTAS DESTACAN LA BAJA DISPONIBILIDAD DE MULTICANCHAS COMO UN ELEMENTO QUE AFECTA EL USO DE ESPACIOS PÚBLICOS}

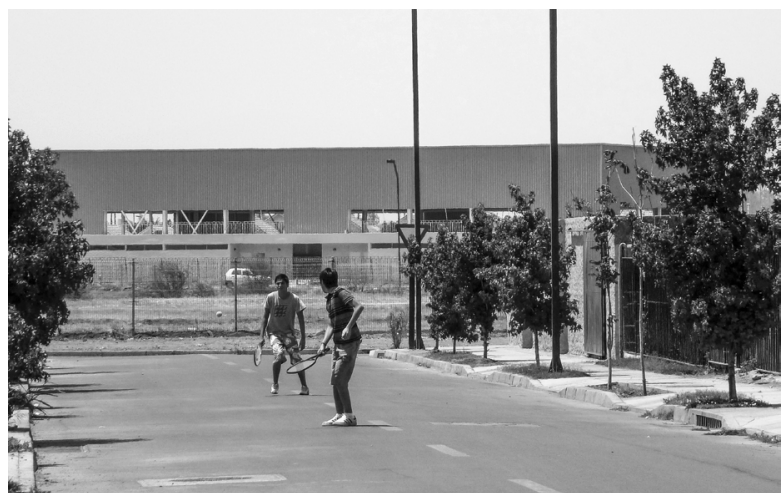

Fuente: Autor

la organización territorial de estas instituciones y la localización de ciudades satélites es señalado como una dificultad por el administrador urbano del proyecto Valle Grande:

Por módulo de crecimiento se va cumpliendo con educación, seguridad y servicios y dentro de ese cabe carabineros. En el caso de Carabineros la planificación impuesta por la norma no va de acuerdo con la planificación que ellos tienen de su plan de ubicación de retenes. Nos han dicho "para nosotros no hay ningún interés y nos interfiere mucho con nuestra manera de planificar que usted me diga, ioiga tengo 20000 habitantes póngame Carabineros! (Administrador urbano del proyecto Valle Grande, septiembre, 2010) 
FIGURA 9. LA CIUDAD SATÉLITE SUPONE EL AUMENTO EN EL COSTO DE VIDA ASOCIADO A LA DISPONIBILIDAD EXCLUSIVA DE EOUIPAMIENTO LOCAL PRIVADO Y LA NECESIDAD DE MOVILIDAD INTENSIVA HACIA SANTIAGO

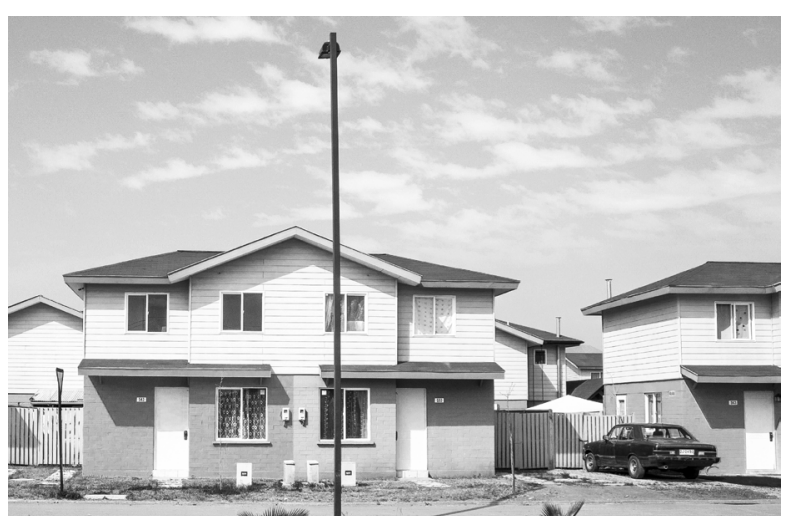

Fuente: Autor

\section{REPRESENTANDO LA CALIDAD DE VIDA, LA FELICIDAD PARADÓJICA DEL HABITANTE DE CIUDAD SATÉLITE}

La ciudad satélite en Lampa muestra un perfil de habitante más ambicioso y exigente con la definición de su entorno residencial. Se relocalizaron en la ciudad satélite motivados por un ideal de "ciudad a la carta". Ser capaces de moldear su vida urbana acorde a sus gustos e intereses. Esto es, habitar la ciudad satélite periurbana, usar selectivamente determinadas autopistas, consumir y socializar en determinados malls; excluyendo al mismo tiempo elementos negativos de la ciudad tradicional como delincuencia, polución, etc. Su éxodo desde el Gran
FIGURA 10. LA CASA EN LA CIUDAD SATÉLITE, AUN GENERANDO ALTA PRECARIEDAD ECONÓMICA PARA UN GRUPO DE HABITANTES, RESULTA UNA CONOUISTA FAMILIAR A LA QUE NO ESTÁN DISPUESTOS A RENUNCIAR

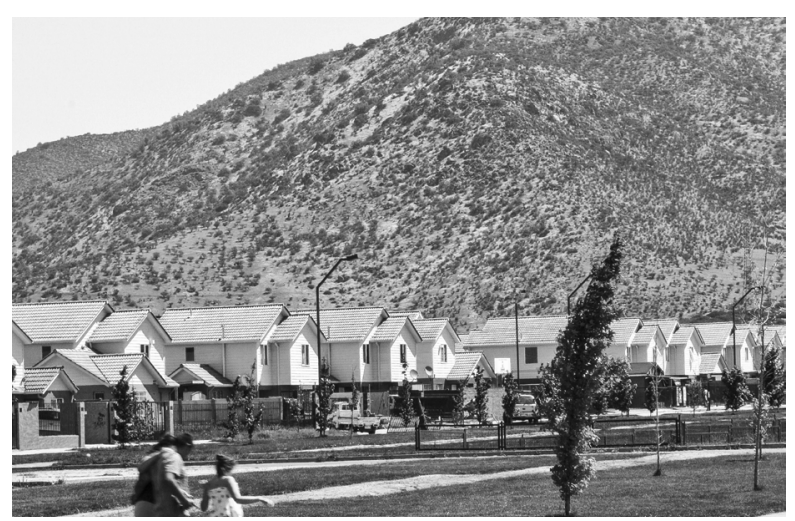

Fuente: Autor

Santiago no representaba el deseo de abandonar la vida urbana sino limpiarla de experiencias no deseadas. Bajo ésta aproximación selectiva, la ciudad satélite, aunque localizada a cuarenta kilómetros de la ciudad y rodeada de plantaciones de alfalfa, constituye la conquista de una vida de barrio. Esta valoración de la ciudad satélite como conquista familiar de una urbanidad superior, se manifiesta en que el 85\% desea permanecer en estos proyectos a largo plazo.

ARTÍCULO: Ciudades satélites periurbanas en Santiago de Chile: paradojas entre la satisfacción residencial y precariedad económica del periurbanita de clase media/ 
Gané en todo, el lugar se da para que tú puedas salir, mi hija me decía "no nos vayamos a la casa, traigamos un mantel y hagamos un picnic [en el parque], parece alfombra el pasto, acá el lugar está para que vayas en familia. Yo vivía cerca del Parque de las Palmeras en Renca... pero aquí no se puede comparar... cielos abiertos, eso no lo ves en otro lado, allá tenía el muro del vecino, los cables, el departamento, la ropa tendida. (Paulina, Larapinta)

Yo por lo menos siempre uso auto y me demoro veinte minutos a Santiago. Hago las compras en el LIDER de Quilicura, para atención médica voy a Santiago, además con la tecnología los pagos los hago por internet. Aquí el problema es la salud, falta un centro médico que trabaje las 24 horas, aquí toda la gente va a Santiago. (...) Yo compré para quedarme, prefiero vivir acá, aunque tenga que pasar en Santiago, aquí es agradable, puedes dormir tranquilo, imagínate este aire...es otra cosa. (Victor, Larapinta)

Esta representación de conquista de atributos residenciales superiores muestra también matices asociados al costo económico de sostener dicho sueño periurbano. Consultados sobre el costo económico subyacente a su vida en la ciudad privada, el $42 \%$ de los entrevistados manifiesta que sostener la vida en la ciudad satélite resulta un problema económico serio. Este costo económico se asocia fundamentalmente al gasto diario en transporte y uso de equipamiento local privado (colegios, clubes deportivos).

ARTÍCULO: Ciudades satélites periurbanas en Santiago de Chile: paradojas entre la satisfacción residencial y precariedad económica del periurbanita de clase media/ César Cáceres Seguel
Yo quisiera irme, volvería a Santiago. Mi vida empeoró porque paso dos horas esperando la micro, echo de menos la conectividad, que no haya colectivo, allá nunca esperaba micro porque me servían todas. (...) Se achica el presupuesto familiar, antes por 500 pesos iba y volvía, ahora necesito 2.200 pesos, para mí es un problema serio. Eso se podría resolver si las micros tuvieran conexión con el Transantiago... Si miras hay muchos letreros de "se vende", hay mucha gente que está vendiendo sus casas, compran su casa, se vienen, pero después se dan cuenta de que el presupuesto no le alcanza. (Aida, Valle Grande)

Si me proyecto aquí, es una opción que tomamos para salir de una comuna complicada como Huechuraba. Gané en sentirme segura, en no sentir ese miedo, gané en calidad de vida, uno lo que está pagando es la tranquilidad no vivir con temor, eso lo gané. Pero he visto mermado mi presupuesto porque todo sube, supermercado, transporte, ha significado encarecer demasiado el costo familiar. Llegó un supermercado pero faltan más colegios porque estás pagando arancel de Providencia para arriba, cuando una familia es numerosa es imposible pagar, por eso saco a mis niñas a estudiar fuera. Es un gasto que se lleva muy justo, viviendo justo con lo que tengo (...) Uno cree en el proyecto porque lo que me vendieron fue tener una mini ciudad, donde no iba a qué tener que moverme a Santiago, pero es a largo plazo, muy a largo plazo. (Tatiana, Valle Grande)

El barrio es precioso... pero lo estoy pensando porque a mi hijo lo estoy postulando al Instituto Nacional y desde acá me queda muy lejos. En unos años más

revista invi № 85 / Noviembre 2015 / Volumen №30: 83-110 101 
me voy porque si tú ves está lejos, yo tengo auto y es mucho gasto, el supermercado te queda lejos... más el dividendo, es complicado. Aquí hay mucha gente que ha devuelto su casa al banco porque no pueden pagar los dividendos. (Johanna, Larapinta)

¿Cómo interpretar esta aparente contradicción entre satisfacción residencial y alta precariedad? Para comprender la percepción de calidad de vida que el habitante encuentra en estos proyectos cabe reconsiderar la idea expuesta por Lipovetsky ${ }^{39}$ sobre que las sociedades actuales gozan de mayor capacidad de consumo pero en contexto de severa precariedad. Aquí propongo definir la experiencia residencial en ciudades satélites de Lampa como la paradojal felicidad del periurbanita de clase media. Ésta se funda en la aparente contradicción entre la satisfacción por la conquista de estándares residencialessuperiores, asociado a una precariedad económica derivada del costo de sostener una vida periurbana basada en una intensiva movilidad y disponibilidad exclusiva de equipamiento barrial privado. Surge un modo de vulnerabilidad asociado a grupos medios experimentando un régimen de urbanidad basado en la privatización de bienes urbanos de uso cotidiano. La conquista de mejores estándares residenciales es real pero lleva asociada una lógica de responsabilidad individual en el acceso a equipamiento y urbanidad básica. Esta privatización de equipamiento urbano

39 Lipovetsky, 2010, p. 13. básico perfila a la ciudad satélite como un espacio residencial configurado bajo lógicas propias de lo que Harvey ${ }^{40}$ define como nuevo capitalismo. No obstante las condiciones impuestas por esta vida condicionada a pago, o "urbanidad trans-bank", la ciudad satélite se representa como un símbolo de un triunfo familiar al que no están dispuestos a renunciar fácilmente. Sin embargo, apenas surja algún episodio económico inesperado, aparecerá el letrero "se vende" anunciando el retorno a la ciudad. Estos reportes sugieren que si bien las últimas décadas los segmentos medios gozan de mayores niveles de bienestar urbano y deciden con mayor libertad donde vivir. Estas nuevas experiencias residenciales encadenan también formas inéditas de precariedad social. Contrario a la noción de suburbio privado como oasis de bienestar urbano, la evidencia de estas entrevistas muestra ciudades satélites como espacios socialmente complejo, espacios caleidoscopios capaces de encarnar tanto bienestar urbano como precariedad social.

\section{Conclusiones}

Las entrevistas muestran un habitante que representa su éxodo a la ciudad satélite como una búsqueda de valores residenciales inaccesibles en sus

40 Harvey, 2005, p. 145. 
barrios de origen. Este habitante no aspira únicamente a las llaves de una casa propia sino a la experiencia de un barrio habitable. Esta expectativa se satisface fundamentalmente mediante la conquista de seguridad y acceso a espacios públicos que promueven nuevas prácticas recreacionales. Sin embargo, para un grupo significativo esta satisfacción residencial ocurre bajo estados de alta precariedad económica. Este estudio constata el surgimiento de una precariedad de grupos medios con débil capacidad sostener una vida urbana basado una alta movilidad y exclusiva disponibilidad de equipamiento privado. Retomando la pregunta inicial, ¿la ciudad satélite representa siempre una conquista de calidad de vida? La ciudad satélite puede interpretarse como espacio-espejo de la realidad de grupos medios en Chile. Un grupo heterogéneo compuesto por segmentos medio-altos con herramientas económicas que lo habilitan para una vida en la periurbia privada, coexistiendo con segmento medio pauperizado, bajo un stress económico dado por las exigencias que impone un nuevo trato de urbanidad en régimen privado. Más que diferencias entre los dos proyectos estudiados (Larapinta y Valle Grande), ambos proyectos evidencian una fragmentación social interna que los convierte en espacios socialmente heterogéneos y complejos.
En un rasgo compartido con otras metrópolis latinoamericanas ${ }^{41}$ este estudio muestra que la expansión periurbana de Santiago se explica sustancialmente como grupos medios presionando por la redefinición de su hábitat urbano. A diferencia del periurbanita de clase alta que ya gozaba de un hábitat de alto estándar, el salto periurbano de segmentos medios se explica por la ambición de dar un salto en su experiencia residencial, alcanzando valores residenciales asociados indisolublemente al binomio hogar-entorno. Conviene no caricaturizar esta aspiración como una búsqueda de status (tendencia observada en algunas publicaciones), más bien entenderla como la aspiración legítima de conquistar estándares residenciales negados en la ciudad tradicional. Compartiendo lo señalado en otros estudios ${ }^{42}$, la búsqueda de seguridad aparece como un factor central en la decisión de relocalización en proyectos periurbanos. Se constata empíricamente el rol que hoy juega el factor miedo en la configuración física y simbólica de la metrópolis de Santiago. A diferencia de lo planteado en estudios sobre la materia, el éxodo hacia la ciudad satélite no debe leerse como una huida de la ciudad, sino precisamente como una búsqueda de urbanidad básica, una demanda por quizás el más urbano de los elementos: el barrio. A diferencia de urbanizaciones periurbanas para estratos altos

41 Arizaga, 2003; Svampa, 2001; Meyer \& Bähr, 2004.

42 Caldeira, 2000; Arizaga, 2003. 
(comuna de Colina), la ciudad satélite estudiada no cabe dentro de la definición exacta de urbanización cerrada o amurallada. Si bien existen condominios o calle cerradas dentro de los casos estudiados, se plantean como proyectos que, o bien constituyen nuevos asentamientos (Valle Grande), o resultan una extensión mejorada-modernizada del tejido urbano de la ciudad de Lampa. Esto es relevante porque, al menos en el caso de Lampa, la ciudad satélite es ante todo una propuesta de asentamiento moldeado desde lo que la empresa entiende por urbanidad superior.

¿Qué implicancias tienen estos hallazgos para la planificación metropolitana en Santiago? La normativa por condiciones (que condiciona la urbanización de proyectos residenciales a la localización de servicios y equipamiento básico) aparece como una normativa exitosa en lograr que el privado internalice los costos asociados a la urbanización. Sin embargo, el reporte del habitante muestra brechas entre el carácter privado del equipamiento (transporte, centro médico, clubes deportivos) y el perfil socioeconómico real del habitante. La precariedad del sueño periurbano para estos grupos solo se superará si estos asentamientos transitan gradualmente a albergar servicios como Transantiago (eliminando el doble pago por tramo), centros médicos con atención Fonasa, variedad de comercio. Se suele argumentar en la discusión urbana chilena, que la dispersión de proyectos residenciales en los

104 revista invi № 85 / Noviembre 2015 / Volumen № 30: 83-110 márgenes metropolitanos respeta la legítima libertad individual de vivir donde la familia desee (ver documento de Cámara Chilena de la Construcción ${ }^{43}$ ). Sin embargo, la evidencia muestra que la generación de ciudad satélites aisladas en el territorio periurbano resulta un modelo de urbanización insostenible en términos sociales y funcionales, ya que necesariamente demandará una mayor dispersión territorial en la inversión del Estado (transporte, salud, educación, policía, etc.) Frente a este modelo de metropolización basado en la generación de nuevos asentamientos cabe preguntarse ¿No resulta más racional permitir el desarrollo de proyectos condicionados únicamente en áreas de expansión de centros periurbanos consolidados como Colina, Lampa, Buin y otros? Esto permitiría la concentración de masa crítica suficiente para la localización de comercio, servicios públicos y transporte en centros periurbanos. Finalmente, el predominio de desarrollo urbano privado en Santiago y otras ciudades medias de Chile, exige mayor investigación sobre el grado de satisfacción que el/la habitante encuentra en los nuevos proyectos residenciales. Es necesaria más investigación para poner a prueba aquel lugar común que representa a proyectos privados como oasis indiscutidos de calidad de vida.

43 “La CChC considera que el diseño de una PNDU debe tener su foco puesto en las personas; en sus necesidades y aspiraciones. Lo anterior implica que la PNDU propicie la posibilidad de elección de los ciudadanos sobre el cómo y dónde quieren vivir" (Giménez y Herrera, 2011, p. 4).

ARTÍCULO: Ciudades satélites periurbanas en Santiago de Chile: paradojas entre la satisfacción residencial y precariedad económica del periurbanita de clase media/ 


\section{Bibliografía}

ARIZAGA, Cecilia. Nuevas urbanizaciones cerradas en los noventa: representaciones del suburbio en sectores medios. Buenos Aires, Instituto de Investigaciones Gino Germani, Facultad de Ciencias Sociales, Universidad de Buenos Aires. 2003.

ARIZTÍA, Tomás. Consumo y sectores medios en Chile de los 90. Santiago, Tesis Instituto de Sociología Universidad Católica de Chile. 2002.

ARRIAGADA, Irma y SOJO, Ana. Las clases medias en América Latina: algunas conjeturas desde la perspectiva de género. Pensamiento Iberoamericano. (10): 221-244, 2012. ISSN 0212-0208.

ASOCIACION Chilena de Empresas de Investigación de Mercado. Grupos socioeconómicos 2008. [En línea]. Asociación Investigadores de Mercado. 2008. Disponible en: http://www.aimchile. cl/wp-content/uploads/2011/12/Grupos_ Socioeconomicos_AIM-2008.pdf

BÁRCENA, Alicia, ed. y SERRA, Narcís, ed. Clases medias y desarrollo en América Latina. [En línea]. Santiago, CEPAL. 2010. ISBN: 978-84-9251123-5. Disponible en: http://www.cepal.org/ publicaciones/xml/4/20354/sps98_lcl2209.pdf.

BAROZET, Emmanuelle y FIERR0, Jaime. Clase media en chile, 1990-2011: algunas implicancias sociales y políticas. [En línea]. Santiago, Fundación Konrad Adenauer. 2011. Serie de Estudios nro. 4. Disponible en: http://www.kas.de/wf/doc/ kas_29603-1522-4-30.pdf?111202200649

ARTíCULO: Ciudades satélites periurbanas en Santiago de Chile: paradojas entre la satisfacción residencial y precariedad económica del periurbanita de clase media/ César Cáceres Seguel
CABRALES, Luis Felipe y CANOSA, Elia. Nuevas formas y viejos valores: urbanizaciones cerradas de lujo en Guadalajara. En: CABRALES, Luis Felipe, coord. Latinoamérica: países abiertos, ciudades cerradas. Guadalajara, Universidad de Guadalajara, UNESCO. 2002. p. 589-590. ISBN 970-27-0194-5.

CALDEIRA, Teresa Pires. City of walls: crime, segregation, and citizenship in São Paulo. California, University of California Press, 2000. ISBN: 9780520221437

CONTRERAS, Dante; COOPER, Ryan; HERMAN, Jorge y NEILSON, Christopher. Movilidad y vulnerabilidad en Chile. [En línea]. En foco. (56), 2005. ISSN 0717-9987. Disponible en: http://www.expansiva. cl/media/en_foco/documentos/12102005130329. pdf

DEMATTEIS, Giuseppe. Suburbanización y periurbanización. Ciudades anglosajonas y ciudades latinas. En: MONCLÚS, F.J., ed. La ciudad dispersa, suburbanización y nuevas periferias. Barcelona, CCCB. 1998, p. 17-33.

DUCCI, María Elena y GONZÁLEZ, Marina. Anatomía de la expansión de Santiago, 1991-2000. En: GALETOVIC, Alexander, ed. Santiago: dónde estamos y hacia dónde vamos. Santiago, Centro de Estudios Públicos. 2006. p. 123-146. ISBN 9567015392.

ESPINOZA, Vicente y BAROZET, Emmanuelle. De qué hablamos cuando decimos "clase media"? Perspectivas sobre el caso chileno. En: JOIGNANT, Alfredo, coord. y GÜELL, Pedro, coord. El arte

revista invi № 85 / Noviembre 2015 / Volumen Nº 30: 83-110 105 
de clasificar a los chilenos. Enfoque sobre los modelos de estratificación en Chile. Santiago, Expansiva UDP, Universidad Alberto Hurtado. 2009. p. 103-130. Serie Políticas Públicas. ISBN 978-956-314-070

FISHMAN, Robert. Bourgeois utopia: the rise and fall of suburbia. New York, Basic Books. 1987.

FRANCO, Rolando; HOPENHAYN, Martín y LEÓN, Arturo. Crece y cambia la clase media en América Latina: Una puesta al día. [En línea]. Revista CEPAL. (103): 7-26, abril 2011. ISSN 02520257. Disponible en: http://www.cepal.org/es/ publicaciones/11446-crece-y-cambia-la-clasemedia-en-america-latina-una-puesta-al-dia

FREY, Hildebrand. Designing the city: towards a more sustainable urban form. London, Taylor \& Francis Group. 1999. ISBN 978-0419221104.

GIMÉNEZ, Pilar y HERRERA, Fernando. Bases para una "política nacional de desarrollo urbano". Propuesta de la CChC para una mejor administración del territorio. [En línea]. CChC. 2011. Disponible en: http://190.2.88.42/minuta/bases-para-una\%E2\% 80\%9Cpolitica-nacional-de-desarrollourbano\%E2\%80\%9D/

GLASZE, Georg. Private neighbourhoods as club economies and shareholder democracies. BelGeo. (1): 87-98, 2003.

HARVEY, David. The new imperialism. Oxford, Oxford University Press, 2005. ISBN 978-0199278084.

HERRERA, Fernando y GIMENEZ, Pilar. Bases para una "política nacional de desarrollo urbano" propuesta de la Cámara Chilena de la Construcción para una mejor administración del territorio. [En línea]. Santiago. Cámara Chilena de la Construcción. 2011. Disponible en: http://www.cchc.cl/wpcontent/uploads/2011/06/DT-N67_PoliticaUrbana-CChC-F.pdf

HIDALG0, Rodrigo y BORSDORF, Axel. Los megaproyectos residenciales vallados en la periferia ¿barrios cerrados autosuficientes 0 nuevas ciudades? Revista Urbano. 8(12): 5-12, 2005. ISSN 0717-3997.

JANOSCHKA, Michael. El nuevo modelo de la ciudad latinoamericana: fragmentación y privatización. [En línea]. Eure. 28(85): 11-20, 2002. Disponible en: http://dx.doi.org/10.4067/ S0250-71612002008500002

KNOX, Paul y PINCH, Steven. Urban social geography. An introduction. London, Prentice Hall. 2006. ISBN 0131249444

LEÓN, Arturo y MARTÍNEZ, Javier. La estratificación social chilena hacia fines del siglo XX. [En línea]. CEPAL. 2001. Serie Políticas Sociales, nro. 52. ISBN 9213218893. Disponible en: http://www.cepal.org/es/publicaciones/6009la-estratificacion-social-chilena-hacia-fines-delsiglo-xx

LIEPINS, Ruth. New energies for an old idea: reworking approaches to community' in contemporary rural studies. [En línea]. Journal of Rural Studies. 16(1): 23-35, 2000. ISSN: 07430167. Disponible en: http://dx.doi.org/10.1016/ S0743-0167(99)00042-X.

ARTÍCULO: Ciudades satélites periurbanas en Santiago de Chile: paradojas entre la satisfacción residencial y precariedad económica del periurbanita de clase media/ 
LIPOVETSKY, Gilles. La felicidad paradójica. Barcelona, Anagrama. 2010. ISBN 978-8433973863.

LIZAMA, Jaime. La ciudad fragmentada: espacio público, errancia y vida cotidiana. Santiago de Chile, Universidad Diego Portales. 2007. ISBN 978-956-314-002-6

MARTINOTTI, Guido. Metropoli, La nuova morfologia sociale della città. Boloña, Il Mulino. 1993

MATTOS, Carlos A. de. Santiago de Chile, globalización y expansión metropolitana: lo que existía sigue existiendo. [En línea]. EURE. 25(76): 2956, 1999. ISSN 0250-7161. Disponible en: http:// dx.doi.org/10.4067/S0250-71611999007600002.

MEYER, Kerstin y BÄHR, Jürgen. La difusión de condominios en las metrópolis latinoamericanas. El ejemplo de Santiago de Chile. Revista de Geografía Norte Grande. (32): 39-53, 2004. ISSN 0379-8682.

MINISTERIO de Vivienda y Urbanismo. Encuesta nacional de calidad de vida urbana. Santiago, MINVU. 2011.

--- Memoria explicativa, modificación Plan Regulador Metropolitano de Santiago, Provincia de Chacabuco. Santiago, MINVU. 1996

MORALES, Liliana y YAÑEZ, Álvaro. La bancarización en Chile, concepto y medición. [En línea]. Superintendencia de Bancos e Instituciones Financieras. 2006. Disponible en: http://www.sbif.cl/ sbifweb3/internet/archivos/publicacion_5291.pdf
MULLIGAN, Gordon; CARRUTHERS, John y CAHILL, Meagan. Urban quality of life and public policy: A survey. [En línea]. Contributions to Economic Analysis. 266: 729-802, 2004. ISSN 05738555. Disponible en: http://dx.doi.org/10.1108/ S0573-8555(2005)0000266024.

OECD. Latin American economic outlook 2011: how middle-class is Latin America? [En línea]. Paris, OECD Development Centre. 2010. ISBN 97892-64-09465-9. Disponible en http://dx.doi. org/10.1787/leo-2011-en

PADDISON, Ronan. Communities in the city. En: PADDISON, Ronan, ed. Handbook of urban studies. London, Sage. 2001. p. 184-205. ISBN 080397695X.

PODUJE, Iván. El globo y el acordeón: planificación urbana en Santiago, 1960-2004. En: GALETOVIC, Alexander, ed. Santiago: dónde estamos y hacia dónde vamos. Santiago, Centro de Estudios Públicos. 2006. p. 231-276. ISBN 9567015392.

ROITMAN, Sonia. Transformaciones urbanas en los 90: los barrios cerrados del área metropolitana de Mendoza. [En línea]. Mundo Urbano. (13), 2004. Disponible en: http://www.mundourbano. unq.edu.ar/index.php/ano-2001/59-numero13/104-5-transformaciones-urbanas-en-los-90los-barrios-cerrados-del-area-metropolitana-demendoza

--- Barrios cerrados y segregación social urbana. [En línea]. Scripta Nova: revista electrónica de geografía y ciencias sociales. 7(146(118)), 2003. ISSN: 1138-9788. Disponible en: http://www. ub.edu/geocrit/sn/sn-146(118).htm

revista invi № 85 / Noviembre 2015 / Volumen Nº 30: 83-110 107 
SALCED0, Rodrigo y TORRES, Alvaro. Gated communities in Santiago: wall or frontier? [En línea]. International Journal of Urban and Regional Research. 28(1): 27-44, 2004. ISSN 1468-2427. Disponible en: http://dx.doi. org/10.1111/j.0309-1317.2004.00501.x

SOCIEDAD Inmobiliaria Valle Grande. Memoria explicativa proyecto de desarrollo urbano Valle Grande. Santiago, Sociedad Inmobiliaria Valle Grande. 2002.

SOCOVESA S.A. Estudio de impacto urbano proyecto Larapinta. Santiago, SOCOVESA. 2003.

SVAMPA, Maristella. Los que ganaron: la vida en los countries y barrios privados. Buenos Aires, Biblos. 2001.

TELLA, Guillermo. La mutación de enclaves urbanísticos en Buenos Aires. Espiral: Estudios sobre Estado y Sociedad. 10(28): 211-237, 2003. ISSN 1665-0565.

TORCHE, Florencia y WORMALD, Guillermo. Estratificación y movilidad social en Chile: entre la adscripción y el logro. [En línea]. Santiago,
CEPAL. 2004. Serie Políticas Sociales nro. 98. ISBN 9213226047. Disponible en: http://repositorio. cepal.org/bitstream/handle/11362/6089/ S0410803_es.pdf?sequence $=1$

URIBE, Hernando. El lugar: entre candados, rejas y miedos. [En línea]. Biblio 3w: revista bibliográfica de geografía y ciencias sociales. 7(393), 2002. ISSN: 1138-9796. Disponible en: http://www. ub.edu/geocrit/b3w-393.htm.

VIDAL, Tomeu y POL, Enric. La apropiación del espacio: una propuesta teórica para comprender la vinculación entre las personas y los lugares. [En línea]. Anuario de psicología. 36(3): 281-298, 2005. ISSN 0066-5126. Disponible en: http:// www.raco.cat/index.php/AnuarioPsicologia/ article/view/61819/81003 